\title{
Regional Practice of Developing Road Safety Behavior Competency in Future Specialists
}

\author{
Roza Sh. Akhmadieva ${ }^{1,2} \&$ Rifkat N. Minnikhanov ${ }^{3}$ \\ ${ }^{1}$ Public Budgetary Institution «Scientific Center for Life Safety», Kazan, Russia \\ ${ }^{2}$ Kazan (Volga region) Federal University, Kazan, Russia \\ ${ }^{3}$ Traffic Police Department of the Ministry of Interior of the Republic of Tatarstan, Kazan, Russia \\ Correspondence: Roza Sh. Akhmadieva, Director of Public Budgetary Institution «Scientific Center for Life \\ Safety», 420059, Orenburgsky trakt, 5, Kazan, Russia. E-mail: roza79.08@mail.ru
}

Received: May 7, 2015 Accepted: May 16, 2015 Online Published: May 28, 2015

doi:10.5539/jsd.v8n3p242 URL: http://dx.doi.org/10.5539/jsd.v8n3p242

\begin{abstract}
Road safety - is one of the principal needs of the person, and to ensure it, the person must view himself as a subject thereof. Thus every person needs to have a developed ability to distinguish and prevent threats, and ensure personal safety when on the road. Training future specialists, capable of teaching road safety behavior to various age-groups of population is becoming one of the most important objectives of professional pedagogy. So the scientific novelty of the article is in: theoretical rationalization of the road safety behavior competence development process in the future specialists that reflects cognitive, disposition and asseptive personality characteristics; a designed model of regional system for ensuring road safety behavior based on participation, continuity, clustering, productivity, personification, prevention principles that covers all social and age-groups of population and directed at establishing a unified regional road safety behavior information and technology environment. Materials of the research can be used for improving educational courses for training future specialists in the field of "Life safety", as well as in developing regional road traffic safety improvement targeted programs and the Federal Road Traffic Safety Improvement Targeted Program for the period until 2020.
\end{abstract}

Keywords: regional practice, road safety behavior, model, competency

\section{Introduction}

Life safety is a dynamic phenomenon reacting timely and adequately to changing hazards and threats in the process of human activity, defining development of basic concepts about dangerous and emergency situations in daily life, conscious and responsible attitude to personal safety and that of others, as well as developing the ability to protect life and health in adverse circumstances, reacting adequately to dangerous situations in light of own limitations (Akhmadiyeva, 2011c; Kuznetsov, 2002; Ilyitskaya et al., 2007).

One of the structural components of life safety is safety of road traffic. Official statistics tells us that over a million humans die in the road accidents every year, with over 50 million being injured. Such a level of traffic injuries costs dearly to the economy, consuming from $1 \%$ to $3 \%$ GDP in most countries. The objective set by European Council of Ministers of Transport (ECMT) for its member countries is to lower traffic accident mortality by 2012 to 50\% of 2000 statistics (Akhmadiyeva, 2011a; Beck, 2000; Belov, 2000; Shtompka, 2005).

Analysis of ensuring road safety behavior-related foreign experience has shown the need of the following conditions: speed control; total prohibition of DUI; using safety belts; improving road quality; improving structural safety of vehicles; decreasing risks for beginning drivers; insuring the car and the driver; developing preventive programs (on safe child transportation to and from school, safety of public transportation and cargo traffic); establishing NCAP information program; conducting United Nations Global Road Safety Week.

The number of road traffic offenses in Russia is 1.5 times higher than the number of vehicles. Driver behavior shows a consistent tendency of growing more aggressive. Driving above speed limit, driving into opposing traffic lane and DUI were the reason for almost $70 \%$ of road accidents with injuries. Russian Federation ministry of economic development estimates annual damage to amount to some 2.5\% GDP. In 2009 the number of Russian Federation deaths in road accidents constituted a third of all mortality in Europe. Analysis of domestic experience in ensuring road traffic safety allowed us to disclose the following conditions of developing road 
safety behavior: development of legal regulatory norms, including federal and regional legislation, decrees of RF President, Government resolutions, "2006-2012 Road Traffic Safety Improvement" Federal Targeted Program; intensifying activities of ministries and departments, responsible for road traffic safety throughout the administrative hierarchy; organizing informational and outreach work to improve legal consciousness, concentrating public attention to road traffic safety issues, internalization of general concepts about dangerous road traffic situations, and consequences for human life and health; intensifying the work with children, teenagers and youth on teaching them safe road behavior rules; improving control and supervision activity in the field of ensuring road traffic safety (Doroguntsov, 2002; Akhmadiyeva, 2011b; Alekhin, 2010).

Analysis of Russian and foreign experience in road traffic safety has shown that road safety behavior developments are related to prevention of dangerous behavior of road users; improving organization of vehicle and pedestrian traffic; improving aid provision of aid to road transport accidents victims. Pedagogical process must be directed towards professional training of future life safety specialists and modular approach to developing road safety behavior competency (Moshkina, 2002; Smirnov, Shakhramanyan \& Kryuchek, 2009; Giddens, 1994; Akhmetshina, Khaliullina \& Minnikhanov, 2003).

The research allow to define various social (constitutional right of a human for protection of life and health; negative influence of road transport accidents on humans, society and finance and economic development of the state, variative models of interaction between road traffic objects and subjects ("human - vehicle", "human road", "human - vehicle - road", "pedestrian - driver", "passenger - driver", "driver - driver"); public opinion monitoring on the issues of road traffic safety; setting up road traffic safety informational and educational websites on the Internet for various audiences; organizing public outreach activities on promoting road safety behavior; discussing problems of life safety at regional, Russian and International scientific conferences, symposiums and seminars) and psychological and pedagogical (need of safety and security \& protection of individual's vital interests from external threats; studying principles of road traffic safety in educational establishments of various levels; including life safety into the list of training areas and specializations of professional education; conducting specialized campaigns ("Attention to kids!", "Attention to pedestrians!", "Polite driver", "Zebra", "Safe wheel", motor rallies to visit the places of famous battles etc.); developing the concept of ensuring road safety behavior in the Republic of Tatarstan for the period through 2020) preconditions for developing road safety behavior.

\section{Methodological Framework}

Modular approach to competency development is considered in the article as a modern correspondent of systemic, integrative, differentiated, akmeologic, contextual approaches, specialized training of future specialists in the integration environment of education, science and production, and defining development of their readiness for effective professional activity. It's noted that modular education approach to competency development defines development of competency models of professional school graduates that must possess a set of knowledge and competencies, ensuring implementation of work in modern information and technology environment; ability to develop own competencies for the purposes of a specific project, adapting quickly towards external changes, discover and define tasks, resolve non-standard problems.

The study described the process of road safety behavior competency development reflecting individual cognitive, dispositional and asseptive characteristics of future specialists. Road safety behavior competency of future specialists is a holistic property of an individual, influencing development of worldview on life; internalizing theoretical knowledge about factors, nature and structure of road traffic safety and psychological knowledge in the amount preparing the individual for safe road behavior; developing an ability to disclose and prevent hazards and ensure personal road safety. Road safety behavior as a competency of a specialist includes the following integral properties of the individual:

- cognitive (from lat. Cognitio - knowledge) - positive thinking; holistic view of road safety behavior; understanding the necessity of following road traffic rules; preventing road threats and hazards, capable of causing irreparable harm (damage) to vital interest of humans;

- dispositional (from lat. dispositio - disposition) - stable attitude of the individual towards road safety behavior; responsible approach towards own safety and that of others; psychological stability in case of dangerous situation or threats that take place on the road;

- asseptive (from lat. aseptivno- openness) - capabilities and skills of ensuring road safety behavior; readiness for preemptive measures to prevent dangers and threats; ability to respond adequately within one's own limitations to various dangerous situations. 
Developed and scientifically substantiated principles of developing road traffic safety behavior competency of future specialist are:

- participation, foreseeing variative forms of social partnership of professional education establishments with ministries, departments and commissions responsible for organization and safety of road traffic, in the process of developing road safety behavior competency of future specialists and regulating renewing components of the competency development in line with changes in the road traffic rules;

- continuity, defining systemic integrity of specialized campaigns ("Green light", "Road sciences school", "School bus", "Auto exams season", "Auto-lady" etc.) and educational programs on the principles of road safety behavior within vertical and horizontal structure of educational process; developing readiness for lifelong learning in students;

- clustering, directed at integrating purpose, motivation, content, process activity, control and evaluation of pedagogical process components of developing future specialist road traffic safety competency;

- productivity, providing future specialist road safety behavior readiness development through participation in designing and implementing scientific educational and scientific production type road safety behavior projects (Young Traffic Inspectors conferences; creation and installation of automatic traffic enforcement systems; developing transport infrastructure; helping injured in traffic accidents; creating road traffic safety information and education websites; kart racing club activities, etc.);

- personification, defining holistic purpose-oriented influence on development of individual's consciousness properties; developing stable and conscious positive attitude towards road traffic safety; defining individual path of road traffic safety competency development of each future specialist;

- prevention, consisting of preemptive measures against possible dangerous behavior of road traffic participants; development of prevention programs and organizing informational outreach to ensure road safety behavior.

The set of these principles provides for systemic integrity of content, form, methods and conditions of the road traffic safety competency development in future specialists.

\section{Results and Discussions}

Developed and substantiated model of regional system of ensuring road safety behavior is presented at Pic. 1 . Qualitative difference of the model is in including different sets of activity on ensuring road safety behavior (interaction between all interested ministries and departments; setting conditions for road traffic safety; organizing public outreach work; organizing continuous education system on the principles of road safety behavior taking into account changing nature of road traffic; improving available equipment and premises), covering all social and age groups of population and is directed at developing unified information and technology space on developing road safety behavior. 




Figure 1. Model of regional system for ensuring road safety behavior

Description of interactions of authorities and public institutions, responsible for ensuring road safety behavior of all road traffic participants, help promote a common good attitude towards road traffic safety in a clear visual manner.

It is defined that the common good "road traffic safety" is a set of material (sources of obtaining information about road traffic safety, educational services on safe road behavior rules training, transport infrastructure, road traffic organization means) and spiritual values (accepting road traffic safety as a global humanitarian value; conscious recognition of road traffic rules priority status; understanding the need to prevent road hazards and threats capable to cause irreparable harm (damage) to vital human interests) related to ensuring road traffic safety. 
Table 1. Variative forms of organizing road safety behavior development by social and age groups

\begin{tabular}{|c|c|c|c|}
\hline \multicolumn{4}{|c|}{ Social and age groups } \\
\hline Preschoolers & $\begin{array}{c}\text { Elementary and middle } \\
\text { school students }\end{array}$ & Youth & Adult population \\
\hline $\begin{array}{l}\text { Learning traffic } \\
\text { rules, } \\
\text { developing } \\
\text { capability to ride a } \\
\text { bicycle; road traffic } \\
\text { rules corner; "Road } \\
\text { traffic ABCs" } \\
\text { didactic game }\end{array}$ & $\begin{array}{l}\text { Capability to ride a bicycle, } \\
\text { learning traffic rules, } \\
\text { learning kart structure and } \\
\text { developing driving skills; } \\
\text { driving classes; contests } \\
\text { ("Safe wheel", "Help first } \\
\text { grader to safety reach } \\
\text { school" etc.); Youth Driving } \\
\text { School (Junior Driving } \\
\text { Schools, DOSAAF) }\end{array}$ & $\begin{array}{l}\text { Vocational driver training } \\
\text { programs; "Auto exams } \\
\text { season" contest; "Safety and } \\
\text { security through the eyes of } \\
\text { the youth" round table; } \\
\text { traffic accident victims } \\
\text { remembrance campaigns; } \\
\text { Professional training in the } \\
\text { area of "Life safety" }\end{array}$ & $\begin{array}{l}\text { Contests ("Green } \\
\text { light", "School of road } \\
\text { sciences"); seminars, } \\
\text { conferences; round } \\
\text { tables; motor rallies to } \\
\text { visit places of famous } \\
\text { battles; instructor } \\
\text { professional development }\end{array}$ \\
\hline
\end{tabular}

Games, Young Traffic Inspectors movement

Learning road safety behavior principles within educational

programs; developing driving and vehicle technical

servicing skills.

\begin{tabular}{l}
\hline Kart racing \\
\hline Learning road traffic rules; contests and campaigns ("Attention to kids!", "Attention to pedestrians!", "Polite \\
drivers", "Zebra" etc.); monitoring public opinion on the road traffic safety; computer games; scientific and \\
procedural methodology materials and creation of thematic TV and Radio programs to promote safe road \\
behavior among various age groups; visits to State Road Traffic Safety Inspectorate museum; development of \\
road safety behavior competence
\end{tabular}

The purpose of using driving simulators for development of road safety behavior competency in future specialists is in internalization and development of knowledge, capabilities, skills and experience in performing tasks related to the competency application in the field of safe road behavior, building on the interaction of all components of the educational process: motivation, purpose, content, process activity, control and supervision. The technology is directed at defining and substantiating the essence of road safety behavior training as a system, at the level of separate disciplines, as well as at its unity with process components (forms, methods). As a result, substantive and procedural parts of the technology are dialectically interrelated (Figure 2). 


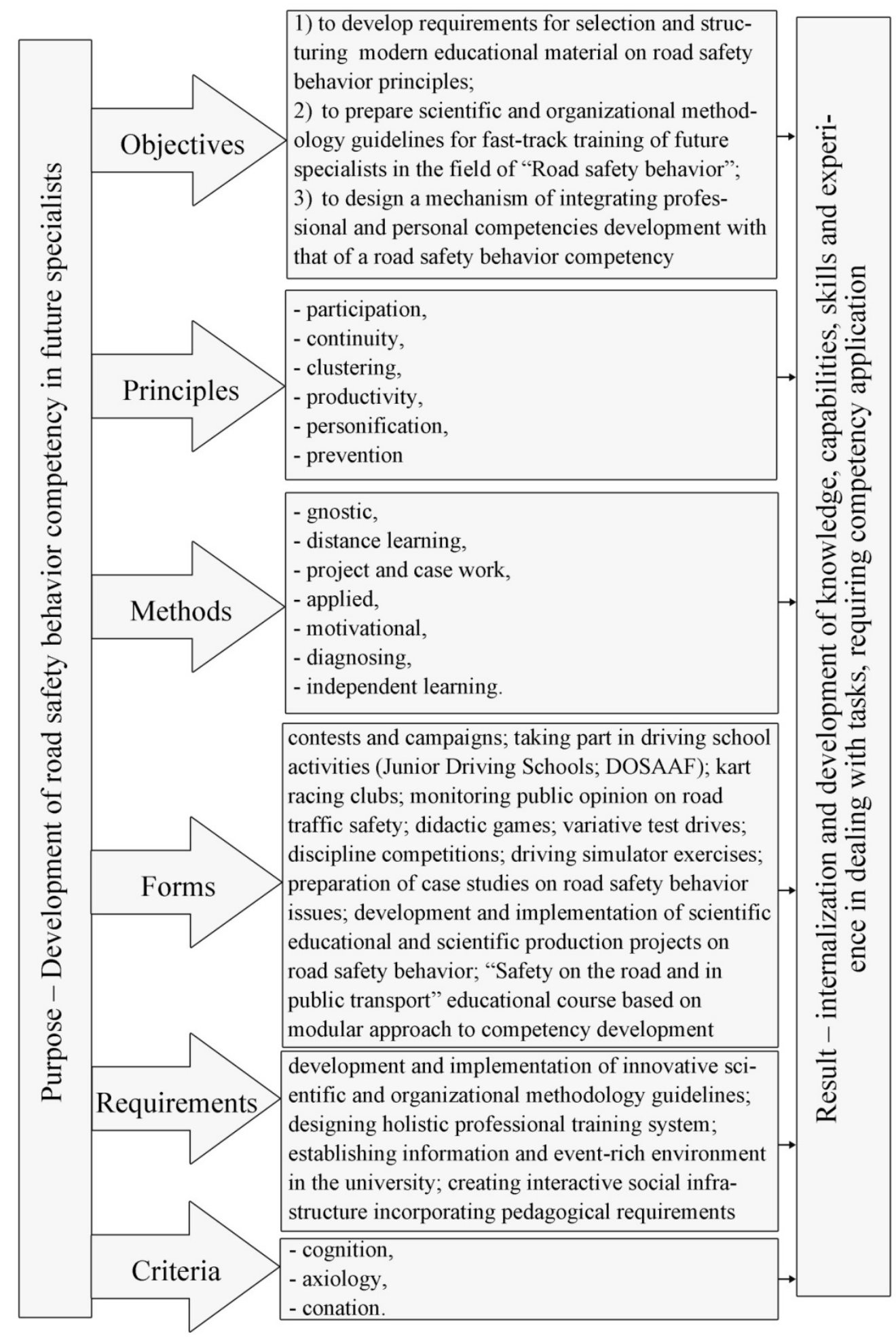

Figure 2. Technology of using driving simulators for developing road safety behavior competency in future specialists

Qualitative difference of using driving simulators for road safety behavior development in future specialists is its purpose-orientated environment, ability to provide self-organization and self-management into education activity of future specialists. The technology allows for simple development of holistic view about road safety behavior, 
helping them to recognize priority importance of following road traffic rules, as well as develop capabilities and skills of safe road behavior, obtain experience of taking preemptive measures within own limitations for prevention of hazards and threats taking place on the road.

The research substantiates modular approach to competency development within "Safety on the road and in public transport" educational course. The purpose of the course is in developing holistic view about road and public transport safety behavior in future specialists, as well as the competency to ensure safe behavior, disclosing and preventing hazards and threats that can take place. The objectives of the course are internalization of basic concepts about dangerous and emergency situations that can take place on the road and in public transport, their consequences for life and health of humans; encouragement and recognition of the need to follow road traffic rules and developing psychological stability in conditions of hazard or threat that can take place on the road or in the public transport; developing capabilities, skills and experience of ensuring safety behavior on the road and public transport, and preventing hazards and threats capable to cause irreparable harm (damage) to vital interests of humans; developing the ability to conduct public outreach activities on the aspects of road traffic safety and prevention of road transport accidents. Objectives and tasks of the course define breakdown into the following modules: "The rules, participants of road traffic and their safety"; "Causes and prevention of road transport injuries"; "Principal causes and methods of preventing road transport accidents. Driver and passengers behaviors in dangerous situations"; "Safety conditions and rules of passenger behavior in city public transport"; "Accident-prone situations, taking place in public transport and rules of safe passenger behavior"; "Accident-prone situations in the metro and rules of behavior"; "Dangerous situations and rules of behavior on the railroad, water and air transport". Procedural methodology of planning and conducting "Safety on the road and in public transport" course lessons to meet requirements of didacticism principles in that they are systemic, scientific, fundamental, holistic, visual, have properties of congruity, continuity, accessibility and individualization.

Monitoring road safety behavior competency development in future specialists is a continuous scientifically substantiated process of diagnosis, evaluation and forecasting degree of internalizing knowledge, capabilities, skills and experience in the field of road traffic safety with a purpose of making strategic decisions of managing specialist training process in the "Life safety" field. This personalized monitoring allows to track dynamics of future specialists professional readiness development to deal with situations requiring road safety behavior competencies. Road safety behavior competency development monitoring is systemic, functional, transparent and comparative, performs diagnostic, corrective and prognostic functions.

\section{Conclusions}

The need to introduce modular approach to professional training program of road safety behavior competency development in future specialists studying in the area of "Life safety" is defined by the growing share of road transport accidents caused by human error, which currently represent over $70 \%$ of the total. The nature of road safety behavior is in being protected from hazards and threats, capable to cause irreparable harm (damage) to vital interests of humans. Road safety behavior includes holistic understanding of the subject, responsible attitude towards personal safety and that of others, readiness to take preemptive measures to prevent hazards and threats, capabilities and skills for ensuring road safety behavior within one's limits. Components of road safety behavior, taking into consideration personal cognitive, dispositional and asseptive characteristics, ensure development of future specialist competency in the field and define their readiness for safe road behavior, as well as influence their civic and moral attitudes, social self-determination and self-improvement, life style.

The concept of using modular approach for development of road safety behavior competency in future specialists includes a set of principles (participation, continuity, clustering, productivity, personification, prevention); a model of regional system for ensuring road safety behavior; a technology of using driving simulators and pedagogical requirements for its implementation (development and installation of innovative scientific and procedural methodology guidelines; designing holistic system of specialist training; establishing information and event-rich environment in the university; integrating pedagogical requirements into interactive social infrastructure); monitoring road safety behavior competency development; as well as criteria (cognition, axiology, conation) and indicators for evaluation of competency level development (competent, knowledgeable, nihilistic) in future specialists.

Technology of modular approach to developing road safety behavior competency in future specialists using driving simulators has purpose-oriented character and foresees learning about factors, nature and structure of road traffic safety in the changing environment; as well as growing capabilities, skills and experience in resolving tasks related to using the competency in the field of safe road behavior through gnostical, 
distant-education, project and case work, applied work, motivation, diagnosing methods and independent learning.

Criteria (cognition, axiology, conation) and indicators for evaluating modular approach in development of road safety behavior competency levels (competent, knowledgeable, nihilistic) describe both cognitive, dispositional and asseptive characteristics of individuals, as well as readiness of future specialists for professional activities in developing road safety behavior competency in all social and age groups. Graduate of professional school specializing in "Life safety" must be capable to understand the dynamics of various road transport situations, protect himself and others around from unfavorable influences defined by the complex interactions within the triangle "traffic participant - control and supervision - road transport environment", as well as master forms and methods of teaching safe road behavior, mechanisms of preparing and conducting specialized contests and campaigns on road traffic safety, creating public outreach materials on obeying road traffic rules.

\section{References}

Akhmadiyeva, R. Sh. (2011a). Development of the traffic health and safety competency in the process of continuous education. Economic and humanitarian researches in regions, 2, 49-54.

Akhmadiyeva, R. Sh. (2011b). Development technology for the traffic health and safety competency with the pedagogue-to-be. Bulletin of Kazan State Technological University, 7, 259-267.

Akhmadiyeva, R. Sh. (2011c). Health and safety on the road as a competency of the graduate of the pedagogy. Economic and humanitarian researches in regions, 3, 35-43.

Akhmetshina, L. G., Khaliullina, I. A., \& Minnikhanov, R. N. (2003). Regional system of prevention of child road traffic injuries in the Republic of Tatarstan. Kazan, 160.

Alekhin, I. A. (2010). Didactic principles of life safety. World of Education - education in the world, 3(39), 3-8.

Beck, W. (2000). Risk Society. Moscow: Progress in tradition, 384.

Belov, S. V. (2000). Heath and safety. Moscow: Higher. wk., 243.

Doroguntsov, S. I. (2002). Management of technogenic and ecological safety in the context of sustainable development paradigm: the concept of system-dynamic solutions. Kiev: Naukova Dumka, 200.

Giddens, E. (1994). Fate, risk and safety. Thesis, 5, 407.

Ilyitskaya, A. V., Belov, S. V., Ilnitskaya, A. V., \& Koziakov, A. F. (2007). Health and Safety. Moscow: Higher School, 616.

Kuznetsov, N. V. (2002). Sociology of security: Building a Culture of Safety in a transforming society. Moscow: Republic, 29.

Moshkina, V. N. (2002). Technology education culture safety of school children in the learning process. Retrieved from http://obrresurs.ru/science/pedagogy/monograf/2glava/

Shtompka, P. (2005). Sociology. Analysis of modern society (C. M. Chervonnaya). Moscow: Logos, 664.

Smirnov, A. T., Shakhramanyan, M. A., \& Kryuchek, N. A. (2009). Health and Safety. Moscow, 375.

\section{Copyrights}

Copyright for this article is retained by the author(s), with first publication rights granted to the journal.

This is an open-access article distributed under the terms and conditions of the Creative Commons Attribution license (http://creativecommons.org/licenses/by/3.0/). 